\title{
Equity and efficiency of maternal and child health resources allocation in Hunan Province, China
}

Minyuan Huang ${ }^{1}$, Dan Luo ${ }^{1 *}$, Zhanghua Wang ${ }^{2}$, Yongmei Cao ${ }^{2}$, Hua Wang ${ }^{3}$, Fengying Bi ${ }^{1}$, Yunxiang Huang ${ }^{1}$ and Luxi Yi ${ }^{2}$

\begin{abstract}
Background: A reasonable allocation of health resources is often characterized by equity and high efficiency. This study aims to evaluate the equity and efficiency of maternal and child health $(\mathrm{MCH})$ resources allocation in Hunan Province, China.

Methods: Data related to $\mathrm{MCH}$ resources and services was obtained from the Hunan maternal and child health information reporting and management system. The Gini coefficient and data envelopment analysis (DEA) were employed to evaluate the equity and efficiency of $\mathrm{MCH}$ resources allocation, respectively.

Results: The MCH resources allocation in terms of demographic dimension were in a preferred equity status with the Gini values all less than 0.3 , and the Gini values for each $\mathrm{MCH}$ resources' allocation in terms of the geographical dimension ranged from 0.1298 to 0.4256 , with the highest values in the number of midwives and medical equipment ( $\geq$ CNY 10,000), which exceeds 0.4 , indicating an alert of inequity. More than $40 \%$ regions in Hunan were found to be relatively inefficient with decreased return to scale in the allocation of $\mathrm{MCH}$ resources, indicating those inefficient regions were using more inputs than needed to obtain the current output levels.

Conclusions: The equity of $\mathrm{MCH}$ resources by population size is superior by geographic area and the disproportionate distribution of the number of medical equipment $(\geq C N Y 10,000)$ and midwives between different regions was the main source of inequity. Policy-makers need to consider the geographical accessibility of health resources among different regions to ensure people in different regions could get access to available health services. More than $40 \%$ of regions in Hunan were found to be inefficient, with using more health resources than needed to produce the current amount of health services. Further investigations on factors affecting the efficiency of $\mathrm{MCH}$ resources allocation is still needed to guide regional health plans-making and resource allocation.
\end{abstract}

Keywords: Maternal and child health resources allocation, Equity, Efficiency, Gini coefficient, Data envelopment analysis, Hunan Province, China

\footnotetext{
*Correspondence: luodan_csu_2011@126.com

'Department of Social Medicine and Health Management, Xiangya School of

Public Health, Central South University, Changsha 410078, People's Republic

of China

Full list of author information is available at the end of the article
}

C C The Author(s). 2020 Open Access This article is licensed under a Creative Commons Attribution 4.0 International License, which permits use, sharing, adaptation, distribution and reproduction in any medium or format, as long as you give appropriate credit to the original author(s) and the source, provide a link to the Creative Commons licence, and indicate if changes were made. The images or other third party material in this article are included in the article's Creative Commons licence, unless indicated otherwise in a credit line to the material. If material is not included in the article's Creative Commons licence and your intended use is not permitted by statutory regulation or exceeds the permitted use, you will need to obtain permission directly from the copyright holder. To view a copy of this licence, visit http://creativecommons.org/licenses/by/4.0/. The Creative Commons Public Domain Dedication waiver (http://creativecommons.org/publicdomain/zero/1.0/) applies to the data made available in this article, unless otherwise stated in a credit line to the data. 


\section{Background}

The maternal and child health $(\mathrm{MCH})$ care is the key component of almost every health system in worldwide. It is also an essential part of the 2030 Sustainable Development Goals (SDGs) proposed by World Health Organization (WHO) in 2015, which includes targets to "reduce the global maternal mortality ratio and deaths of newborns and children under 5 years of age" [1]. In China, after the annunciation of the universal "twochild" policy (a policy allowing all couples to have two children) in October 2015, the need and demand for $\mathrm{MCH}$ services has been increasing accordingly [2]. The Chinese government has been attaching great importance to MCH and issued "Healthy China 2030", a national health plan, in 2016, with a primary goal of improving the health status of mothers and children [3].

There has been a remarkable improvement in $\mathrm{MCH}$ in China over the last decades. The maternal deaths declined from 111.0 per 100,000 live births in 1990 , to 21.8 per 100,000 live births in 2015, and the mortality rate for children under 5 years of age also went down from 54.1 per 1000 live births to about 12.5 per 1000 live births during the same period [4]. However, the progress has been uneven and inequitable at different regions, with higher maternal and child mortality rates in lowand middle-income areas [4]. While there have been studies suggesting that these geographic disparities may result in part from the differences in the degree of equity and efficiency in allocating $\mathrm{MCH}$ resources among different regions $[5,6]$.

Equity in the health resources allocation means that the way health resources distributed among the health care departments or regions can reflect the degree of health fairness [7]. The efficiency refers to the relationship between health inputs and health outcomes. Efficient health resources allocation means that how to produce the greatest health outcomes for a given set of health resources or how they generate the ideal health outcomes using minimal resources [8]. Ensuring equity and efficiency in the allocation of health resources is one of the basic conditions to achieve the equitable, effective and quality health services for mothers and children.

The question about how health resources should be allocated, so that they are distributed in both the most equitable and most efficient way should be an important concern in $\mathrm{MCH}$ system. Studies to date, however, have mainly focused on the equity and efficiency of health resources allocation in primary health care $[9,10]$, overall health care $[11,12]$, or specific health-care institutions such as public hospitals [13] and county hospitals [6]. Although some studies focus on the $\mathrm{MCH}$ resources allocation in China, most studies was conducted in lower- or higher- income regions, with little information available in the middle-income regions [14-17].
Whereas, assessing the equity and efficiency in $\mathrm{MCH}$ resources allocation in different regions is necessary because the problems of determining the appropriate allocation of $\mathrm{MCH}$ resources between regions at different levels of economic development may be different.

Hunan Province $\left(24^{\circ} 39^{\prime}-30^{\circ} 08^{\prime} \mathrm{N}, 108^{\circ} 47^{\prime}-114^{\circ} 15^{\prime} \mathrm{E}\right)$, located in the central south of China, covers an area of around 212, $204 \mathrm{~km}^{2}$ and has a population of approximately 74 million as of 2017. The estimate of the gross domestic product (GDP) per capita for Hunan in the same year is about 49,558 yuan, which is regarded as a typical middle-economic-level area according to the rankings of provincial GDP per capita in China [18]. It includes 14 regions with Changsha as its capital. In 2017, there are $137 \mathrm{MCH}$ hospitals (MCHHs) at different levels in Hunan, including 1 provincial-, 14 municipal- and 122 county-level MCHHs. The maternal and under-five mortality rate in Hunan in 2017 were 12.7 per 100,000 live births and 4.86 per 1000 live births respectively, which are 2.24 and 1.84 two times higher, respectively, than the rates in Beijing, a developed eastern region in China $[19,20]$. There is an urgent need to evaluate the equity and efficiency of $\mathrm{MCH}$ resources allocation in Hunan to provide the scientific basis of regional health planning to narrow the regional disparities in $\mathrm{MCH}$ outcomes.

The evaluation of equity and efficiency in the allocation of $\mathrm{MCH}$ resources is an important part that can help health planners and decision-makers identify bottlenecks and take appropriate actions to further optimize the allocation of limited health resources. This study aimed to assess the equity and efficiency of the $\mathrm{MCH}$ resources allocation in Hunan, China, to explore potential measures for optimizing the $\mathrm{MCH}$ resources allocation.

\section{Methods \\ Data sources and statistical analysis}

The geographic area data was sourced from the $14 \mathrm{mu}-$ nicipal government websites in Hunan. Data related to $\mathrm{MCH}$ resources and services as well as the population numbers (2017) was obtained from the Hunan maternal and child health information reporting and management system. This system is a network data reporting system for Hunan maternal and child health surveillance which was established in 2004. The data in this system is originally collected by the staff responsible for maternal and child care in primary health care institutions and then upload it to the system, which is further audited and managed by Health Commission of Hunan Province. The administrative permission from Health Commission of Hunan Province is required to access and use the data in this system. We had received permission to use these data before data analysis in this study. 
Microsoft Excel 2016 was used to calculate the Gini coefficient, and DEAP (V2.1) was employed to conduct the data envelopment analysis (DEA) [12].

\section{Gini coefficient}

The Gini coefficient is regarded as a superior tool for evaluating the equity of health resources allocation in demographic and geographical dimensions [21]. It is derived from the Lorenz curve, indicating the ratio of the area between Lorenz Curve and the $45^{\circ}$ line to the whole area below the $45^{\circ}$ line. The formula to calculate the Gini coefficient is presented as follows [9]:

$$
G=1-\sum_{i=0}^{k-1}\left(Y_{i+1}+Y_{i}\right)\left(X_{i+1}-X_{i}\right)
$$

$Y_{i}$ is the cumulative percentage of $\mathrm{MCH}$ resources (the eight indicators to assess the equity) in the ith region; $X_{i}$ is the cumulative percentage of population or geography in the $i t h$ region; $k$ is the total number of regions; $G$ is the value of the Gini coefficient.

The value of Gini ranges from 0 to 1 , with higher score indicating greater inequity. Generally, a value of 0 means the absolute equitable allocation of resources; < 0.3 represents preferred equity status; $0.3-$ 0.4 is the normal condition; $>0.4$ refers to an alert of inequity (relative inequity); and $>0.6$ indicates a severe inequity $[10,21]$.

\section{DEA model}

DEA is a non-parametric method that can evaluate the relative efficiency of decision-making units (DMUs), incorporating the multiple input and output variables [22]. The Charnes, Cooper, and Rhodes model (CCR model) and the Banker, Charnes, and Cooper model (BCC model) are considered as the two most superior tools to measure the relative efficiency [12]. The CCR model assumes that production is constant return to scale and can calculate the overall efficiency score, while the BCC model assumes that production is variable return to scale which can further decompose the overall efficiency score of the CCR model into pure technical and scale efficiencies.

In addition, the projection value of the input and output indicators of the inefficient DMUs can be also estimated by BCC model. By measuring the distance from the inputs and outputs of inefficient DMUs to their efficient peers, we could calculate the over-supplied inputs and expected outputs for the inefficient DMUs, which can provide the quantitative basis for improving the efficiency of $\mathrm{MCH}$ allocation of each DMU. Thus, we preferred to select the BCC model in this study to evaluate the efficiency of $\mathrm{MCH}$ resources allocation $[9,23]$.
DEA models include input- and output-oriented models. An input-oriented model reflects the degree to which a DMU can reduce its input without changing its outputs, while an output-oriented model indicates the degree to which a DMU can expand its output without changing its inputs [24]. In this study, the outputs are associated with the quantity of maternal and child health services. With the implementation of the "two-child policy", the demand for maternal and child health services has been increasing [2]. Thus, we chose output-oriented model.

In this study, every region of Hunan Province was assumed as a DMU, with 14 DMUs in total. We used the algebraic sum of the inputs/outputs of all the MCHHs to estimate the efficiency at a region level, except for the system management rate for children under 3 years old. An averaged system management rate was calculated for each of the regions. The number of $\mathrm{MCHHs}$ in 14 regions of Hunan is shown in Table 1. By taking Changsha as an example, Changsha has $11 \mathrm{MCHHs}$, the number of beds in Changsha region is the sum of the beds of 11 MCHHs, totaling 2409 beds in Changsha.

The efficiency status of 14 DMUs was estimated by the values of overall efficiency, technical efficiency and scale efficiency. Overall efficiency means that under the same circumstances, the actual output levels of a DMU is similar to the ratio of maximum output [11]. Technical efficiency is the ratio of the minimum input to the actual input levels of a DMU for a given set of outputs, keeping the input proportion constant [11]. Scale efficiency represents the constant evaluation of the scale return, the multiple output increase as equivalent to the increase in multiple inputs [11]. The following is a formula showing the relationship between the three [11]:

\section{Overall efficiency $=$ Technical Efficiency $*$ Scale Efficiency}

The value of overall efficiency, technical efficiency and scale efficiency all range from 0 to 1 . When overall efficiency is 1 , the DMU is relatively efficient; when technical efficiency is 1 , but scale efficiency and overall efficiency are less than 1, the DMU is weakly efficient; when the overall efficiency ranges from 0 to 1 , the DMU is inefficient [12].

\section{Indicators}

A comprehensive literature review was conducted in the process of indicators selection [11-13, 25]. Additionally, experts including health administrators working in Health Commission of Hunan Province, the $\mathrm{MCH}$ doctors working in Hunan Provincial Maternal and Child Health Care Hospital were invited to review the rational of indicators selection by telephone consultations. 
Table 1 The number of MCHHs in 14 regions of Hunan in 2017

\begin{tabular}{|c|c|c|c|c|}
\hline Regions & Provincial - level & Municipal - level & County-level & Total number \\
\hline Changsha & 1 & 1 & 9 & 11 \\
\hline Xiangtan & 0 & 1 & 5 & 6 \\
\hline Zhuzhou & 0 & 1 & 9 & 10 \\
\hline Yueyang & 0 & 1 & 9 & 10 \\
\hline Changde & 0 & 1 & 8 & 9 \\
\hline Chenzhou & 0 & 1 & 11 & 12 \\
\hline Hengyang & 0 & 1 & 12 & 13 \\
\hline Yiyang & 0 & 1 & 6 & 7 \\
\hline Loudi & 0 & 1 & 5 & 6 \\
\hline Zhangjiajie & 0 & 1 & 4 & 5 \\
\hline Yongzhou & 0 & 1 & 11 & 12 \\
\hline Huaihua & 0 & 1 & 13 & 14 \\
\hline Shaoyang & 0 & 1 & 12 & 13 \\
\hline Xiangxi & 0 & 1 & 8 & 9 \\
\hline Total number & 1 & 14 & 122 & 137 \\
\hline
\end{tabular}

\section{Equity}

A total of 8 indicators were selected in this study to evaluate the equity in $\mathrm{MCH}$ resources allocation. Human resources and capital are regarded as the important input/output variables in the delivery of health services [9]. The number of doctors, nurses, midwives, and administrative staff members represents human resources, and the MCHHs, beds, operating areas, medical equipment with a value of $\geq$ CNY 10,000 (above \$1420) represents the capital. Medical equipment ( $\geq$ CNY 10,000) is also an important indicator reflecting the hardware investments. The definition of equity indicators is shown in Table 2.

\section{Efficiency}

In terms of efficiency assessment, 4 indicators including the number of health personnel, beds, operating areas, and the number of medical equipment ( $\geq$ CNY 10,000) were selected as inputs. The first indicator represents human resources, and other three represent capital. Another 3 output indicators are the number of live births, outpatients and emergency visits, system management

Table 2 Definition of equity indicators

\begin{tabular}{|c|c|}
\hline Variable & Definition \\
\hline Number of MCHHs & At the end of the year, the sum number of maternal and child health hospitals. \\
\hline Number of beds & The practical beds in MCHHs (also referred to the number of actual beds). \\
\hline Operating areas & $\begin{array}{l}\text { At the end of the year, all housing areas of } \mathrm{MCHH} \text { s except for the residences of employees, includes the } \\
\text { areas for medical services, public health services, medical education and scientific research, logistical } \\
\text { support, administrative management and hospital life facilities. }\end{array}$ \\
\hline $\begin{array}{l}\text { Number of medical equipment with a } \\
\text { value of } \geq \text { CNY } 10,000\end{array}$ & $\begin{array}{l}\text { At the end of the year, the amount of medical equipment with a unit price exceeding CNY } 10,000 \text { in } \\
\text { MCHHs. }\end{array}$ \\
\hline Number of doctors & $\begin{array}{l}\text { At the end of the year, the sum of doctors and assistant doctors in MCHHs who have obtained } \\
\text { registration certificates and are actually engaged in disease prevention and control, medical treatment, } \\
\text { or maternal and child health care. }\end{array}$ \\
\hline Number of nurses & $\begin{array}{l}\text { At the end of the year, the sum of nurses who have obtained the certificate of registered nurses and are } \\
\text { actually engaged in nursing work in } \mathrm{MCHHs} \text {. }\end{array}$ \\
\hline Number of midwives & $\begin{array}{l}\text { At the end of the year, the sum of health personnel who have received professional education in } \\
\text { midwifery, mastered normal delivery, neonatal treatment, dystocia treatment, and basic theoretical } \\
\text { knowledge and skills in maternal and child health. }\end{array}$ \\
\hline Number of administrative staff members & $\begin{array}{l}\text { At the end of the year, the sum of the staff members who are responsible for leading or managing tasks } \\
\text { in medical and health institutions, includes those who are engaged in the management of medical } \\
\text { tasks, public health, medical scientific research and teaching, and those who are engaged in the } \\
\text { administrative work of party and government, personnel, finance, statistics, information, security, and so } \\
\text { on. }\end{array}$ \\
\hline
\end{tabular}


Table 3 Definition of efficiency indicators

\begin{tabular}{|c|c|c|}
\hline Category & Variable & Definition \\
\hline \multirow[t]{4}{*}{ Input } & Number of health personnel & $\begin{array}{l}\text { At the end of the year, the sum of registered doctors, registered assistant doctors, registered } \\
\text { nurses, pharmacists, laboratory and imaging technicians, health supervisors and probationers in } \\
\text { MCHHs. }\end{array}$ \\
\hline & Number of beds & $\begin{array}{l}\text { The practical beds in medical and health institutions (also referred to as the number of actual } \\
\text { beds). }\end{array}$ \\
\hline & $\begin{array}{l}\text { Number of medical equipment with a } \\
\text { value of } \geq \text { CNY } 10,000\end{array}$ & $\begin{array}{l}\text { At the end of the year, the amount of medical equipment with a unit price exceeding CNY 10, } \\
000 \text { in } \mathrm{MCHHs.}\end{array}$ \\
\hline & Operating areas & $\begin{array}{l}\text { At the end of the year, all housing areas of MCHHs except for the residences of employees. This } \\
\text { includes areas for medical services, public health services, medical education and scientific } \\
\text { research, logistical support, administrative management and hospital life facilities. }\end{array}$ \\
\hline \multirow[t]{3}{*}{ Output } & Number of live births & $\begin{array}{l}\text { The number of newborns of more than } 28 \text { weeks' gestation age with one of the four vital signs } \\
\text { after delivery: breathing, heart beats, pulsation of the umbilical cord and definite movements of } \\
\text { voluntary muscles. }\end{array}$ \\
\hline & $\begin{array}{l}\text { Number of outpatients and emergency } \\
\text { visits }\end{array}$ & The number of patients having outpatient and emergency diagnostic services. \\
\hline & $\begin{array}{l}\text { System management rate for children } \\
\text { under } 3 \text { years old }\end{array}$ & $\begin{array}{l}\text { The proportion of children under } 3 \text { years of age receiving regular physical examinations within } \\
\text { the stipulated time. }\end{array}$ \\
\hline
\end{tabular}

rate for children under 3 years old. The definition of efficiency indicators is shown in Table 3.

\section{Results}

\section{General information on $\mathrm{MCH}$ resources}

There were $137 \mathrm{MCHHs}$ in Hunan Province in 2017, which includes an operating area of 1,169,480 square meters and a total of 13,141 beds. The total number of $\mathrm{MCH}$ workers were 11, 626, including 8224 doctors, 1087 nurses, 1164 midwives and 1151 administrative personnel. Additionally, the number of medical equipment ( $\geq$ CNY 10,000) was 18,441 (See Additional file 1 for further detail).

\section{The equity of $\mathrm{MCH}$ resources allocation}

The $\mathrm{MCH}$ resources allocation in terms of demographic dimension were in a preferred equity status with the Gini values all less than 0.3. The most equitable resource allocation was the number of $\mathrm{MCHHs}$ with the lowest Gini value (0.1325) and the most inequitable was midwives with the highest Gini value (0.2950).

The Gini values for each $\mathrm{MCH}$ resources' allocation in terms of the geographical dimension ranged from 0.1298 (highest equity) in the number of $\mathrm{MCHHs}$ to 0.4256 (lowest equity) in the number midwives. The allocation equity of medical beds, operating areas, doctors, nurses and administrative personnel allocation was in a normal condition, with Gini values fluctuating between 0.3 and 0.4 . While the Gini value for midwives and medical equipment ( $\geq$ CNY 10,000) was 0.4256 and 0.4077 , respectively, which exceeds 0.4 , indicating an alert of inequity.

In general, the $\mathrm{MCH}$ resources allocation seem to be more equitable in the demographic dimension than that in the geographical dimension. Except for the MCHHs, the Gini values for the allocation of doctors, nurses, midwives, administrative personnel, operating areas and medical equipment ( $\geq$ CNY 10,000) per thousand persons were generally lower than that in terms of per square kilometers. The Gini values for $\mathrm{MCH}$ resources allocation based on demographic and geographical dimensions are shown in Table 4.

\section{The efficiency of $\mathrm{MCH}$ resources allocation}

Table 5 presents the efficiency values in $\mathrm{MCH}$ health resources allocation of the 14 regions in Hunan Province. The average scores of overall efficiency, technical efficiency, and scale efficiency in the 14 regions were 0.900 , 0.991 and 0.907 , respectively. Among the 14 regions, 4 regions (28.6\%), including Changsha, Hengyang, Zhangjiajie and Xiangxi, had overall efficiency scores of 1 , indicating that the $\mathrm{MCH}$ resources allocation in these regions is relatively efficient. Another 4 regions (28.6\%), including Zhuzhou, Xiangtan, Shaoyang and Chenzhou,

Table 4 The Gini values for MCH resources allocation in Hunan in 2017

\begin{tabular}{|c|c|c|c|c|c|c|c|c|}
\hline $\begin{array}{l}\text { The Gini } \\
\text { coefficient }\end{array}$ & $\mathrm{MCHHS}$ & $\begin{array}{l}\text { Number of } \\
\text { beds }\end{array}$ & $\begin{array}{l}\text { Operating } \\
\text { area }\end{array}$ & $\begin{array}{l}\text { Medical } \\
\text { equipment * }\end{array}$ & $\begin{array}{l}\text { Number of } \\
\text { doctors }\end{array}$ & $\begin{array}{l}\text { Number of } \\
\text { nurses }\end{array}$ & Midwives & $\begin{array}{l}\text { Administrative } \\
\text { personnel }\end{array}$ \\
\hline Demographic & 0.1325 & 0.2107 & 0.2222 & 0.2790 & 0.1923 & 0.2253 & 0.2950 & 0.2250 \\
\hline Geographical & 0.1298 & 0.3673 & 0.3358 & 0.4077 & 0.3395 & 0.3767 & 0.4256 & 0.3498 \\
\hline
\end{tabular}

${ }^{*}$ Number of medical equipment ( $\geq$ CNY 10,000) 
Table 5 Efficiency values and returns-to-scale characteristics of the 14 regions in Hunan in 2017

\begin{tabular}{llllll}
\hline DMUs & Overall efficiency & Technical efficiency & Scale efficiency & Type of scale inefficiency & Relatively efficiency status \\
\hline Changsha & 1.000 & 1.000 & 1.000 & - & Efficient \\
Hengyang & 1.000 & 1.000 & 1.000 & - & Efficient \\
Zhangjiajie & 1.000 & 1.000 & 1.000 & - & Efficient \\
Xiangxi & 1.000 & 1.000 & 1.000 & - & Efficient \\
Zhuzhou & 0.962 & 1.000 & 0.962 & Drs & Weakly efficient \\
Xiangtan & 0.912 & 1.000 & 0.912 & Drs & Weakly efficient \\
Shaoyang & 0.960 & 1.000 & 0.960 & Drs & Weakly efficient \\
Chenzhou & 0.903 & 1.000 & 0.903 & Drs & Weakly efficient \\
Changde & 0.756 & 0.984 & 0.769 & Drs & Inefficient \\
Huaihua & 0.782 & 0.947 & 0.826 & Drs & Inefficient \\
Loudi & 0.784 & 0.979 & 0.801 & Drs & Inefficient \\
Yueyang & 0.793 & 0.983 & 0.807 & Drs & Inefficient \\
Yongzhou & 0.876 & 0.990 & 0.884 & Drs & Inefficient \\
Yiyang & 0.878 & 0.996 & 0.881 & Drs & I \\
Mean & 0.900 & 0.991 & 0.907 & & Inefficient
\end{tabular}

Drs Decreasing return to scale

had technical efficiency scores of 1 , but overall and scale efficiency scores of less than 1, indicating the $\mathrm{MCH}$ resources allocation in these regions is weakly efficient when compared with efficient regions. Additionally, the other 6 regions (42.8\%), including Yueyang, Changde, Yiyang, Yongzhou, Huaihua and Loudi, had overall efficiency, technical efficiency and scale efficiency scores of less than 1, suggesting that the $\mathrm{MCH}$ resources allocation in these regions was inefficient. Among the 10 relatively scale-inefficient regions, all of them had decreasing return to scale (DRS), indicating that these regions had scales that were too large and needed to cut down their operations to achieve constant returns to scale.

In the BCC model, we also calculated the projection value of the input and output indicators of the inefficient regions (Table 6). The inefficient regions should either decrease their inputs or increase their outputs to improve the efficiency of $\mathrm{MCH}$ resources allocation. The result from input-output projection analysis of Changde, for example, indicates that, in order to achieving a relatively optimal resources allocation, Changde could reduce the average number of health personnel by 104.3 , the average number of beds by 45.91 and the average number of medical equipment ( $\geq$ CNY 10,000 ) by 251.7 , when keeping its present output levels unchanged. Alternatively, Changde needs to increase the average number of live births by 281.2, the outpatient and emergency visits by 128 , 874.1 and the system management rate for children under 3 years old by an average of $1.48 \%$ at the current input levels.

\section{Discussion}

The evaluation of equity in the allocation of $\mathrm{MCH}$ resources in Hunan showed that the Gini values by population were all lower than those by geographic area, suggesting a larger disparity exists in the geographic allocation of $\mathrm{MCH}$ resources than in the demographic allocation. The same result has been found in many previous studies $[7,10,21]$. One possible explanation for this finding is that government take the number of health resources per thousand persons, instead of per $10,000 \mathrm{~km}^{2}$, as the priority for health resources allocation in China $[9,12]$. It may have also contributed to the geographic disparities in the accessibility of healthcare services [26], which is incompatible with the goal of "Universal Health Coverage" advocated by WHO that recommends every people could get access to affordable and quality healthcare services [27]. The government should focus more on the inequity of resources allocation in terms of geographical dimension when making the health planning, and improve the accessibility of $\mathrm{MCH}$ for people living in the remote and economically underdeveloped regions.

The Gini values for the number of medical equipment $(\geq \mathrm{CNY} 10,000)$ and midwives by geographic area exceeded 0.4 , indicating the distribution of these two resources were inequitable among different regions. The medical equipment $(\geq \mathrm{CNY} 10,000)$ is representative a higher-quality health service that plays a critical role in patient's diagnosis and treatment, such as the positron emission computed tomography, gamma knife and linear accelerators [28]. While a proportion of people may need to travel long distances in order to access necessary 
Table 6 Input-output projection analyses in 6 inefficient regions

\begin{tabular}{|c|c|c|c|c|c|c|c|c|}
\hline Regions & & $Y_{1}$ & $Y_{2}$ & $Y_{3}$ & $X_{1}$ & $x_{2}$ & $x_{3}$ & $X_{4}$ \\
\hline \multirow[t]{4}{*}{ Changde } & Actual value & $17,456.00$ & $939,513.00$ & 91.57 & 1689.00 & 1042.00 & $85,664.52$ & 1560.00 \\
\hline & Projection value & $17,737.21$ & $1,068,387.10$ & 93.05 & 1584.70 & 996.09 & $85,664.52$ & 1308.30 \\
\hline & Insufficient or redundancy value & 281.21 & $128,874.1$ & 1.48 & -104.3 & -45.91 & 0.00 & -251.7 \\
\hline & Insufficient or redundant rate (\%) & 1.61 & 13.72 & 1.62 & -6.18 & -4.41 & 0.00 & -16.13 \\
\hline \multirow[t]{4}{*}{ Huaihua } & Actual value & 8138.00 & $768,498.00$ & 88.35 & 1534.00 & 806.00 & $122,455.80$ & 1149.00 \\
\hline & Projection value & $12,589.82$ & $811,314.76$ & 93.27 & 1191.84 & 760.21 & $67,589.84$ & 1023.26 \\
\hline & Insufficient or redundancy value & 4451.82 & $42,816.76$ & 4.92 & -342.16 & -45.79 & $-54,865.96$ & -125.74 \\
\hline & Insufficient or redundant rate (\%) & 54.70 & 5.57 & 5.57 & -22.31 & -5.68 & -44.81 & -10.94 \\
\hline \multirow[t]{4}{*}{ Loudi } & Actual value & $16,147.00$ & $742,479.00$ & 89.70 & 1693.00 & 1101.00 & $69,414.12$ & 1415.00 \\
\hline & Projection value & $16,490.74$ & $758,285.04$ & 91.61 & 1413.68 & 856.35 & $69,414.12$ & 1049.72 \\
\hline & Insufficient or redundancy value & 343.74 & $15,806.04$ & 1.91 & -279.32 & -244.65 & 0.00 & -365.28 \\
\hline & Insufficient or redundant rate (\%) & 2.13 & 2.13 & 2.08 & -16.50 & -22.22 & 0.00 & -25.81 \\
\hline \multirow[t]{4}{*}{ Yueyang } & Actual value & $20,694.00$ & $1,003,192.00$ & 91.22 & 2058.00 & 1151.00 & $96,494.00$ & 1759.00 \\
\hline & Projection value & $21,059.18$ & $1,207,652.05$ & 92.83 & 1846.92 & 1151.00 & $96,494.00$ & 1464.42 \\
\hline & Insufficient or redundancy value & 365.18 & $204,460.05$ & 1.61 & -211.08 & 0.00 & 0.00 & -294.58 \\
\hline & Insufficient or redundant rate (\%) & 1.76 & 20.38 & 1.76 & -10.26 & 0.00 & 0.00 & -16.75 \\
\hline \multirow[t]{4}{*}{ Yongzhou } & Actual value & $14,395.00$ & $780,164.00$ & 91.94 & 1343.00 & 831.00 & $88,198.56$ & 1043.00 \\
\hline & Projection value & $14,536.86$ & $806,190.70$ & 92.93 & 1333.10 & 831.00 & $70,611.25$ & 1043.00 \\
\hline & Insufficient or redundancy value & 141.86 & $26,026.70$ & 0.99 & -9.9 & 0.00 & $-17,587.31$ & 0.00 \\
\hline & Insufficient or redundant rate (\%) & 0.99 & 3.34 & 1.1 & -0.74 & 0.00 & -19.94 & 0.00 \\
\hline \multirow[t]{4}{*}{ Yiyang } & Actual value & $17,231.00$ & $714,132.00$ & 90.73 & 1537.00 & 866.00 & $71,227.00$ & 1474.00 \\
\hline & Projection value & $17,292.63$ & $822,524.68$ & 91.06 & 1422.99 & 866.00 & $71,227.00$ & 1076.99 \\
\hline & Insufficient or redundancy value & 61.63 & $108,392.68$ & 0.33 & -114.01 & 0.00 & 0.00 & -397.01 \\
\hline & Insufficient or redundant rate (\%) & 0.36 & 15.18 & 0.36 & -7.42 & 0.00 & 0.00 & -26.93 \\
\hline
\end{tabular}

Positive number represents insufficient rate, negative number represents redundancy rate

$Y_{1}$ Number of live births; $Y_{2}$ Number of outpatients and emergency visits; $Y_{3}$ System management rate for children under 3 years old

$X_{1}$ Number of health personnel; $X_{2}$ Number of beds; $X_{3}$ Operating areas; $X_{4}$ Number of medical equipment $(\geq$ CNY 10,000$)$

examination and treatment due to the inequitable allocation of $\mathrm{MCH}$ resources by geographic area, and this will therefore affect the improvement of their health outcomes [11]. Policy makers need to consider the geographical accessibility of health services when planning the number of medical devices at different regions. Midwives are the backbone of $\mathrm{MCH}$ system, playing a vital role in providing health services for mothers and children [29]. However, midwives in China even in the world are insufficient in total quantity [30, 31]. Additionally, it is normal that health-workers tend to serve in developed regions with better economic conditions and more opportunities for career development, which may further enlarge the gaps in the number of midwives between different regions. Increasing the number of well-educated and trained midwives will be the key to the achievement of universal health coverage [31].

Less than one-third regions in Hunan achieved high efficiency in the allocation of $\mathrm{MCH}$ resources. While more than $40 \%$ of regions were found to be relatively inefficient in the allocation of $\mathrm{MCH}$ resources with decreased return to scale, suggesting that those inefficient regions were using more health resources than needed to produce the current amount of health services. Results from the input-output projection value analysis showed that the relative inefficient $\mathrm{MCH}$ resources allocation are concentrated on the economically underdeveloped regions in Hunan (e.g., Huaihua, Yongzhou) [19]. According to the projection value of input indicators, almost all inefficient regions had input redundancies, especially in the number of health-workers and medical equipment ( $\geq C N Y 10,000)$. From the projection value of output indicators, the number of outpatients and emergency visits, live births and systematic management rate for children under 3 years old still had a lot of room for improvement, particularly the number of outpatients and emergency visits.

There are several possible explanations for this result. One possibility is that the demand of health care services for mothers and children had been overestimated, 
leading to the input redundancy of $\mathrm{MCH}$ resources in these inefficient regions. This possibility may be very small but could not be neglected in the decision-making process. The health institutions in China had been granted autonomy with extremely few government subsidies, during the 1970s- early 2000s market-oriented health reform period [32, 33]. Affected by market competition, they vastly expanded investment, including operating areas extension, beds installation, and the purchase of medical equipment [6]. A previous survey reported that the proportion of using large-scale medical devices was less than $50 \%$ in many provinces in China [6]. The under-utilized invested hardware facilities may cause considerable health resources to be wasted, thereby decrease the overall efficiency of resources allocation. This suggests that the potential redundancy of $\mathrm{MCH}$ resources should be noticed when health administrators make regional health plans.

Another possibility is that many families prefer to attend $\mathrm{MCHHs}$ in well-developed areas, rather than the local $\mathrm{MCHHs}$, to seek higher-quality $\mathrm{MCH}$ services, such as tertiary MCHHs in Changsha city in Hunan. Because $\mathrm{MCHHs}$ in economically developed areas have more qualified personnel and technical advantages [34]. This phenomenon, in some extent, is suggestive of the regional inequity of the distribution of $\mathrm{MCH}$ resources and health utilization, that well-developed regions have more experienced experts and advanced equipments than that in underdevelopment regions. An approach may be helpful to improve the quality of health care services in $\mathrm{MCHHs}$ in underdeveloped regions, by sharing training activities in developed regions [35]. It may be useful to improve the quality of medical care in the economic backward areas in a sustainable manner, that medical personnel return to work after a period of receiving the technical training from tertiary hospitals in developed regions.

For the inefficient regions, transferring their excessive input resources to more available health services for mothers and children is another reasonable method to improve the efficiency of $\mathrm{MCH}$ resources allocation. The gaps in the performance of $\mathrm{MCHHs}$ between different regions may be another factor leading to the fact that the amount of services produced by $\mathrm{MCHHs}$ in these inefficient regions, given the same level of inputs, was relatively smaller, compared to the counterparts in efficient regions. In this regard, focus should be on strengthening capacity for increased services delivery. The $\mathrm{MCHHs}$ in inefficient regions are primarily tasked with improving staff performance and the quality of their management practices in order to effectively utilize inputs and provide available health care services for the mothers and children in economically backward areas [36].
In fact, the real reasons for the inefficiency of $\mathrm{MCH}$ resources allocation are complex. Multiple factors such as the demand of health services, geographical distribution, quality of medical care, hospital management and patient preference should be considered to optimize the allocation of health resources. Further investigations on the factors that will influence the efficiency of $\mathrm{MCH}$ resources allocation is needed before government make a decision on whether decrease health resources or increase health services to improve efficiency of the $\mathrm{MCH}$ resources allocation.

There are several limitations in this study. First, we could not observe the changes in equity and efficiency of $\mathrm{MCH}$ resources allocation in Hunan over time because only 1-year data was used in this study. Longitudinal data should be collected in future studies to provide more valuable information for policy makers to improve the health status for mothers and children. Second, although the selection of indicators is based on the published literature review and expert opinions, other indicators associated with health resources allocation, such as the number of discharged patients and systematic management coverage for pregnant women, were not investigated in this study. Future studies should consider additional indicators to have a comprehensive evaluation of the $\mathrm{MCH}$ resources allocation. Third, when estimating the efficiency of $\mathrm{MCH}$ resources allocation at a regional level, the sum of inputs/outputs of all MCHHs in each region was used to estimate the efficiency scores of each region (DMU), except for the indicator of system management rate for children under 3 years old. An averaged value was regarded as the system management rate of each region. Although this data processing method has been commonly used in previous studies [9, 11, 12], this estimated result may merely reflect the overall health resources allocation at a region level while may be inconsistent with the real situation of each hospitals. The efficiency evaluation of each $\mathrm{MCHH}$ need to be further studied.

\section{Conclusions}

The equity of $\mathrm{MCH}$ resources by population size is superior by geographic area and the disproportionate distribution of the number of medical equipment $(\geq$ CNY 10,000) and midwives between different regions was the main source of inequity. Policy-makers need to consider the geographical accessibility of health resources among different regions to ensure people in different regions could get access to available health services. More than $40 \%$ of regions in Hunan were found to be inefficient with decreased return to scale in the allocation of $\mathrm{MCH}$ resources, suggesting that 
those inefficient regions were using more health resources than needed to produce the current amount of health services. Further investigations on factors affecting the efficiency of $\mathrm{MCH}$ resources allocation is still needed to guide regional health plans-making and resource allocation.

\section{Supplementary information}

Supplementary information accompanies this paper at https://doi.org/10. 1186/s12913-020-05185-7.

Additional file 1. The distribution of maternal and child health care resources in Hunan in 2017. Table. The general information on maternal and child health care resources distribution in Hunan in 2017.

\section{Abbreviations}

MCH: Maternal and child health;; DEA: Data envelopment analysis;

SDGs: Sustainable Development Goals;" WHO: World Health Organization;" GDP: Gross Domestic Product; MCHHs: Maternal and child health hospitals; DMU: Decision-making unit; CCR model: The Charnes, Cooper, and Rhodes model;" BCC model: The Banker, Charnes, and Cooper model;"

DRS: Decreasing return to scale

\section{Acknowledgements}

The authors would like to express gratitude to the staff of Health Commission of Hunan Province and Hunan Provincial Maternal and Child Health Care Hospital, for their kindest contributions and assistances to this study.

\section{Authors' contributions}

LD contributed to the conceptualization and design of the study. HMY, HYX and LD drafted the manuscript and made all revisions. Authors WZH, CYM, $\mathrm{WH}, \mathrm{BFY}, \mathrm{YLX}$ contributed to the data analysis and the interpretation of the data, and provided critical input in the manuscript editing process. All authors read and approved the final manuscript.

\section{Funding}

This study was supported by Major Scientific and Technological Projects for collaborative prevention and control of birth defects in Hunan Province (2019SK1010, 2019SK1011) and the Scientific Research Project of Health Commission of Hunan Province (A20182001). The funders played no role in the design of the study and collection, analysis, and interpretation of data and in writing the manuscript.

\section{Availability of data and materials}

The datasets used and analysed during the current study are available from the corresponding author on reasonable request.

\section{Ethics approval and consent to participate}

Health Commission of Hunan Province granted us permission to use data from Hunan maternal and child health information reporting and management system.

\section{Consent for publication}

Not applicable.

\section{Competing interests}

The authors declare that they have no competing interests.

\section{Author details}

'Department of Social Medicine and Health Management, Xiangya School of Public Health, Central South University, Changsha 410078, People's Republic of China. ${ }^{2}$ Health Commission of Hunan Province, Changsha 410008, People's Republic of China. ${ }^{3}$ Hunan Provincial Maternal and Child Health Care Hospital, Changsha 410008, People's Republic of China.
Received: 7 December 2019 Accepted: 3 April 2020

Published online: 15 April 2020

\section{References}

1. World Health Organization. Transforming our world: the 2030 agenda for sustainable development. New York: WHO; 2015.

2. Liu Y, Qin Q, Xiao Y, Li H, Guang S, Tao S, Hu Y. Changes of second-time mothers and their infants under the universal two-child policy in Changsha. Chin Midwifery. 2019;77:32-6.

3. Tan X, Zhang Y, Shao H. Healthy China 2030, a breakthrough for improving health. Glob Health Promot. 2019;26:96-9.

4. Liang J, Li X, Kang C, Wang Y, Kulikoff XR, Coates MM, Ng M, Luo S, Mu Y, Wang $X$, et al. Maternal mortality ratios in 2852 Chinese counties, 19962015, and achievement of millennium development goal 5 in China: a subnational analysis of the global burden of disease study 2016. Lancet. 2019;393:241-52.

5. Shen Y, Yan H, Reija K, Li Q, Xiao S, Gao J, Zhou Z. Equity in use of maternal health services in Western rural China: a survey from Shaanxi province. BMC Health Serv Res. 2014;14:155.

6. Gai RY, Zhou CC, Xu LZ, Zhu M, Wang XZ, Li SX, Zheng WG, Song PP, Yang $X \mathrm{~L}$, et al. Health resource allocation and productive efficiency of Chinese county hospitals: data from 1993 to 2005. Bioscience Trends. 2010:4:218-24.

7. Liu W, Liu Y, Twum P, Li SX. National equity of health resource allocation in China: data from 2009 to 2013. Int J Equity Health. 2016;15:68.

8. Lotfi F, Kalhor R, Bastani P, Zadeh NS, Eslamian M, Dehghani MR, Kiaee MZ. Various indicators for the Assessment of Hospitals' Performance Status: differences and similarities. Iran Red Crescent Med J. 2014;16:4.

9. Zhang Y, Wang Q, Jiang T, Wang J. Equity and efficiency of primary health care resource allocation in mainland China. Int J Equity Health. 2018;17:140.

10. Zhang T, Xu YJ, Ren JP, Sun LQ, Liu CJ. Inequality in the distribution of health resources and health services in China: hospitals versus primary care institutions. Int J Equity Health. 2017;16:42.

11. Zhang $X Y$, Zhao L, Cui Z, Wang YG. Study on Equity and Efficiency of Health Resources and Services Based on Key Indicators in China. Plos One. 2015:10:12.

12. Sun J, Luo H. Evaluation on equality and efficiency of health resources allocation and health services utilization in China. Int J Equity Health. 2017; 16:127.

13. Zheng W, Sun $H$, Zhang $P$, Zhou G, Jin Q, Lu X. A four-stage DEA-based efficiency evaluation of public hospitals in China after the implementation of new medical reforms. Plos One. 2018:13:10.

14. Lianfeng $\mathrm{L}$, Xiong $\mathrm{Z}$, Lifeng $\mathrm{H}$. Analysis of the allocation fairness and utilization efficiency of maternal and child health care resources in Guangxi during 2013. Mater Child Health Care Chin. 2015:30:4093-6.

15. Shaohui W, Wei W, et al. Analysis of the efficiency of the municipal materna and child health centers in Guangdong Province. Med Soc. 2015:28:10-2.

16. Jiang $X B$, Xing D, Tian QF. Analysis of MCH health resource allocation efficiency in Henan in 2012 based on DEA. Mater Child Health Care China. 2014;29:329-32.

17. Yan X, Zhihong S, et al. Evaluation on the efficiency of country levels of maternity and child care institutions in Jiangsu by DEA. Mater Child Health Care Chin. 2013:28:4607-10.

18. National Bureau of Statistics of China. China statistical yearbook 2018 Beijing: China Statistics Press; 2018.

19. Hunan Provincial Bureau of Statistics. Hunan statistical yearbook 2018. Beijing: China Statistics Press; 2018.

20. Beijing Municipal Bureau of Statistics. Beijing statistical yearbook 2018 Beijing: China Statistics Press; 2018.

21. Jin J, Wang JX, Ma XY, Wang YD, Li RY. Equality of medical health resource allocation in China based on the Gini coefficient method. Iran J Public Health. 2015:44:445-57.

22. Rosko MD. Measuring technical efficiency in health care organizations. J Med Syst. 1990;14:307-22.

23. Wang X, Luo H, Qin X, Feng J, Gao H, Feng Q. Evaluation of performance and impacts of maternal and child health hospital services using data envelopment analysis in Guangxi Zhuang autonomous region, China: a comparison study among poverty and non-poverty county level hospitals. Int J Equity Health. 2016:15:131.

24. Obure CD, Jacobs R, Guinness L, Mayhew S, Vassall A. Does integration of HIV and sexual and reproductive health services improve technical efficiency in Kenya and Swaziland? An application of a two-stage semi 
parametric approach incorporating quality measures. Soc Sci Med. 2016;151: $147-56$.

25. Kreng VB, Yang $C T$. The equality of resource allocation in health care under the National Health Insurance System in Taiwan. Health Policy. 2011;100: 203-10.

26. Chen $Y$, Yin Z, Xie Q. Suggestions to ameliorate the inequity in urban/rural allocation of healthcare resources in China. Int J Equity Health. 2014;13:34.

27. World Health Organization. Universal health coverage (UHC). https://www. who.int/en/news-room/fact-sheets/detail/universal-health-coverage-(uhc). Accessed 24 Jan 2019.

28. Sun J, Gu H, Wen Q, Luo H. Assessing equity in the distribution of hightechnology medical equipment in Guangxi: evidence from an ethnic minority region in southern China. Int J Equity Health. 2017;16:81.

29. Van Lerberghe W, Matthews Z, Achadi E, Ancona C, Campbell J, Channon A, de Bernis L, De Brouwere V, Fauveau V, Fogstad H, et al. Country experience with strengthening of health systems and deployment of midwives in countries with high maternal mortality. Lancet. 2014;384:1215-25.

30. Yin Y, Li J, Lu H, Yao J, Hou R. Essential competencies for three grades of midwives in China. Int J Nursing Sci. 2018;5:18-23.

31. World Health Organization. Nursing and midwifery. https:/www.who.int/ news-room/fact-sheets/detail/nursing-and-midwifery?from=singlemessage. Accessed 9 Jan 2020.

32. Wu Y. China's health care sector in transition: resources, demand and reforms. Health policy. 1997;39:137-52.

33. Bloom G, Xingyuan G. Health sector reform: lessons from China. Soc Sci Med. 1997;45:351-60.

34. Liu G, Xue Y, Qian Z, Yang L, Yang Y, Geng Q, Wang X. Healthcare-seeking behavior among pregnant women in the Chinese hierarchical medical system: a cross-sectional study. Int J Equity Health. 2019;18:129.

35. Sahin B, Ilgun G. Assessment of the impact of public hospital associations (PHAs) on the efficiency of hospitals under the ministry of health in Turkey with data envelopment analysis. Health Care Manag Sci. 2019;22:437-46.

36. Bergen N, Ruckert A, Kulkarni MA, Abebe L, Morankar S, Labonte R. Subnational health management and the advancement of health equity: a case study of Ethiopia. Glob Health Res Policy. 2019;4:12.

\section{Publisher's Note}

Springer Nature remains neutral with regard to jurisdictional claims in published maps and institutional affiliations.

Ready to submit your research? Choose BMC and benefit from:

- fast, convenient online submission

- thorough peer review by experienced researchers in your field

- rapid publication on acceptance

- support for research data, including large and complex data types

- gold Open Access which fosters wider collaboration and increased citations

- maximum visibility for your research: over $100 \mathrm{M}$ website views per year

At $\mathrm{BMC}$, research is always in progress.

Learn more biomedcentral.com/submissions 